\title{
Cases of Brought in Dead Patients in the Accident and Emergency Unit of a Referral Hospital in the Western Region of Ghana
}

\author{
Verner N. Orish ${ }^{*}$, Joseph Y. Ansong², Isaac B. Anagi ${ }^{3}$, Onyekachi S. Onyeabor ${ }^{4}$, \\ Chuku Okorie $^{5}$, Adekunle 0. Sanyaolu ${ }^{6,7}$, Nnaemeka C. Iriemenam ${ }^{7}$ \\ ${ }^{1}$ Department of Internal Medicine, Effia-Nkwanta Regional Hospital, Sekondi-Takoradi, Ghana \\ ${ }^{2}$ Department of Paediatrics, Effia-Nkwanta Regional Hospital, Sekondi-Takoradi, Ghana \\ ${ }^{3}$ Department of Clinical Nutrition, Effia-Nkwanta Regional Hospital, Sekondi-Takoradi, Ghana \\ ${ }^{4}$ Department of Community Health and Preventive Medicine, The Satcher Health Leadership Institute, \\ Morehouse School of Medicine, Atlanta, USA \\ ${ }^{5}$ Department of Epidemiology and Biostatistics, Saint James School of Medicine, Anguilla, BWI \\ ${ }^{6}$ Department of Medical Microbiology \& Immunology, Saint James School of Medicine, Anguilla, BWI \\ ${ }^{7}$ Department of Medical Microbiology and Parasitology, College of Medicine, University of Lagos, Lagos, Nigeria \\ Email: orishv@yahoo.com
}

Received 7 November 2014; revised 13 December 2014; accepted 29 December 2014

Copyright (C) 2014 by authors and OALib.

This work is licensed under the Creative Commons Attribution International License (CC BY). http://creativecommons.org/licenses/by/4.0/

(c) (i) Open Access

\section{Abstract}

The objective of this study was to evaluate cases of brought in dead (BID) patients in the accident and emergency unit of Effia-Nkwanta Regional Hospital through a retrospective study of a period of 3 years. A retrospective descriptive study of BID cases from the death register and patients' records of the accident and emergency unit of the hospital was carried out from January 2011 to December $2013.31 \%(180 / 574)$ of BID cases were recorded over the study period with the age range from below 1 year to over 70 years. They were $58.5 \%$ male and $41.5 \%$ female with a ratio of 1.4:1. The majority of the BID cases $(20.7 \%)$ were patients above 70 years and most cases $(40.8 \%)$ have no known clinical condition associated with the death. The majority of the unexplained deaths were highest among young adults between the ages 30 and 40 years $(22.6 \%)$. The highest cases of BID $(20 \%)$ were seen in the month of December and majority of the cases $(72.5 \%)$ lived within the metropolis. This study showed a concerning trend of BID cases in the hospital with a high prevalence among the elderly and unexplained death among the young adults. Hence there is an urgent need to upgrade hospitals in the area with the hope of relieving the burden off Effia-Nkwanta Regional Hospital and also a need to increase health promotion strategies among the people of the area so as to instill health seeking behavior in order to prevent avoidable deaths.

\footnotetext{
${ }^{*}$ Corresponding author.
}

How to cite this paper: Orish, V.N., Ansong, J.Y., Anagi, I.B., Onyeabor, O.S., Okorie, C., Sanyaolu, A.O. and Iriemenam, N.C. (2014) Cases of Brought in Dead Patients in the Accident and Emergency Unit of a Referral Hospital in the Western Region of Ghana. Open Access Library Journal, 1: e1179. http://dx.doi.org/10.4236/oalib.1101179 


\title{
Keywords
}

\author{
Ghana, Brought in Dead, Health Seeking Behavior
}

\author{
Subject Areas: Epidemiology, Global Health, Public Health
}

\section{Introduction}

Brought in dead (BID) or dead on arrival (DOA) are patients who are brought into hospital without any registrable heart activity and any other vitals suggesting life as verified by the attending physician [1]. The usual entry point into the hospital for these patients in Ghana and elsewhere is the Accident and Emergency Unit. It is a fairly common clinical scenario for patients to be brought in dead in the Emergency Unit in this area.

It is a well-established fact that the Accident and Emergency Unit of a hospital is a true reflection of the kind of care being given to patients that visit the hospital [2]. Consequently, hospital mortality in this unit is used to evaluate the manpower and skills of the health care personnel that give care in the hospital [2] [3]. This is not the case of BID, as there is nothing the hospital or its staff can do for such a patient, hence no medical responsibility on their part [4]. Thus, BID is strongly related to pre-hospital factors, like distance to the hospital, seriousness and severity of clinical condition or nature of injury [2].

There is limited literature on the BID cases, as most research studies have focused on the mortality pattern of cases in the Accident and Emergency Unit with emphasis on expertise of the available manpower. Though this is important, it is also important to look at the BID patients and factors that may influence and contribute to this occurrence in the population. The main objective of this study was to evaluate the prevalence, pattern of distribution and other factors among BID patients in the Accident and Emergency Unit of Effia-Nkwanta Regional Hospital over a 3-year retrospective study period.

\section{Materials and Methods}

\subsection{Study Site}

This was a retrospective observational study carried out in the Emergency Unit of the Effia-Nkwanta Regional Hospital, Sekondi-Takoradi metropolis in the western region of Ghana. Sekondi-Takoradi metropolisis a twin city located in the South-Western part of Ghana. Sekondi-Takoradi is the administrative capital of the Western Region with a land area of 385 square kilometers. It is also approximately 280 kilometers from Cote d'Ivoire border with an estimated population of 335,000 inhabitants. Effia-Nkwanta Regional Hospital is a secondary healthcare institution and serves all other hospitals within the entire 22 districts of the western region. The accident and emergency unit of this hospital attends to medical, surgical, orthopedic and pediatric emergencies, while obstetrics and gynecological emergencies are seen at the maternal health department.

\subsection{Data Collection}

Mortality information in the hospital for the 3-year study period was utilized for analysis. Data were collected retrospectively from patient's records that were brought in dead from January 2011 to December 2013. List of BID patients were collected from the death register and subsequently patients' record were retrieved from the records department. Information on the age, sex, date, time, and month brought to the hospital and any clinical ailment being suffered by patient, if any, were also recorded. Resident location was also collected from the patients' record. Location of patient was grouped into two in terms of the location within or outside the metropolis. Data were double-entered in Microsoft Excel 2010 version and SPSS version 16 and all statistical analysis were done using SPSS.

\section{Results}

The total mortality for the 3 years under study was 574 . There were 150 deaths in 2011 , out of which 40 were BID. In 2012, there were 208 deaths and 68 were BID and in 2013, a total of 216 deaths were recorded with 72 
BID cases (Figure 1). Taken together, $31 \%$ of the total mortality were BID, while $69 \%$ were hospital mortality.

In general, a total of one hundred and eighty patients were brought in dead over three years period. However, among the BID, only 130 patients had their records available for data entry comprising of 58\% (76/130) male and $41.2 \%(54 / 130)$ females with a male to female ratio of 1.4:1 (Table 1).

BID cases were recorded between the age-range below 1 year to over 70 years, with lowest cases $2.3 \%(3 / 130)$ seen in older children between 6 - 11 years and the highest cases $20 \%(26 / 130)$ seen in patient above 70 years (Figure 2).

Over twenty different clinical conditions were associated with the BID cases in this study but majority of the cases $40.8 \%$ (53/130) had no known clinical conditions as they were probably apparently healthy individuals before they died suddenly (Figure 3). This information is based on the history given by the relatives or friends that accompanied the body to the accident and emergency unit.

Anemia, hypertension and its complications, chronic alcoholism and chronic liver disease were the commonest clinical conditions associated with the brought in dead cases in this study (Figure 3). Figure 4 shows the distribution of the clinical condition by age groups. Cases without any associated ailment or clinical condition were more in persons above 30 years, and highest $22.6 \%(12 / 53)$ in the age group from 30 to 40 years.

Figure 5 shows the distribution of BID cases in months. There were two notable peaks in the month of July (19/136) and December (26/130). However, the highest numbers of cases were seen in the month of December.

Majority of the cases $30.5 \%$ came between the hours of 7 am and 12 noon, and also majority of these cases $63.4 \%$ came during the week days (Table 2). Most cases $72.5 \%$ that were BID lived within the metropolis (Table 2).

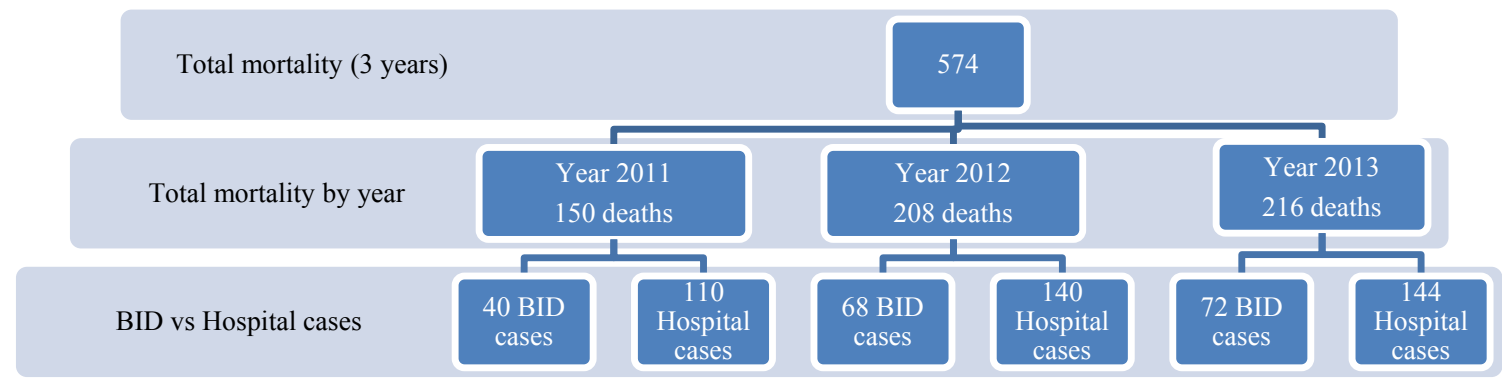

Figure 1. Flowchart of mortality distribution for the 3-year period.

Table 1. Age and sex distribution.

\begin{tabular}{cccc}
\hline Age (Years) & Male & Female & Total \\
\cline { 2 - 4 } $0-5$ & 6 & 7 & 13 \\
$6-11$ & 2 & 1 & 3 \\
$12-19$ & 3 & 3 & 6 \\
$20-30$ & 7 & 1 & 8 \\
$31-40$ & 11 & 7 & 18 \\
$41-50$ & 9 & 8 & 17 \\
$41-60$ & 12 & 6 & 18 \\
$61-70$ & 15 & 6 & 26 \\
70 and above & 11 & 15 & 130 \\
\hline Total & 76 & 54 & \\
\hline
\end{tabular}




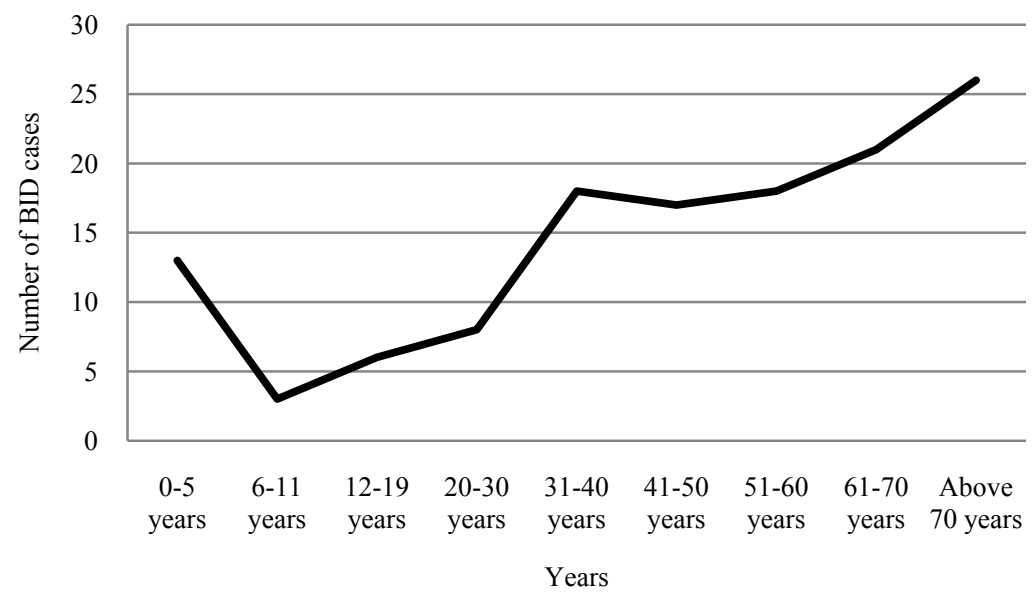

Figure 2. Age distribution of BID patients.

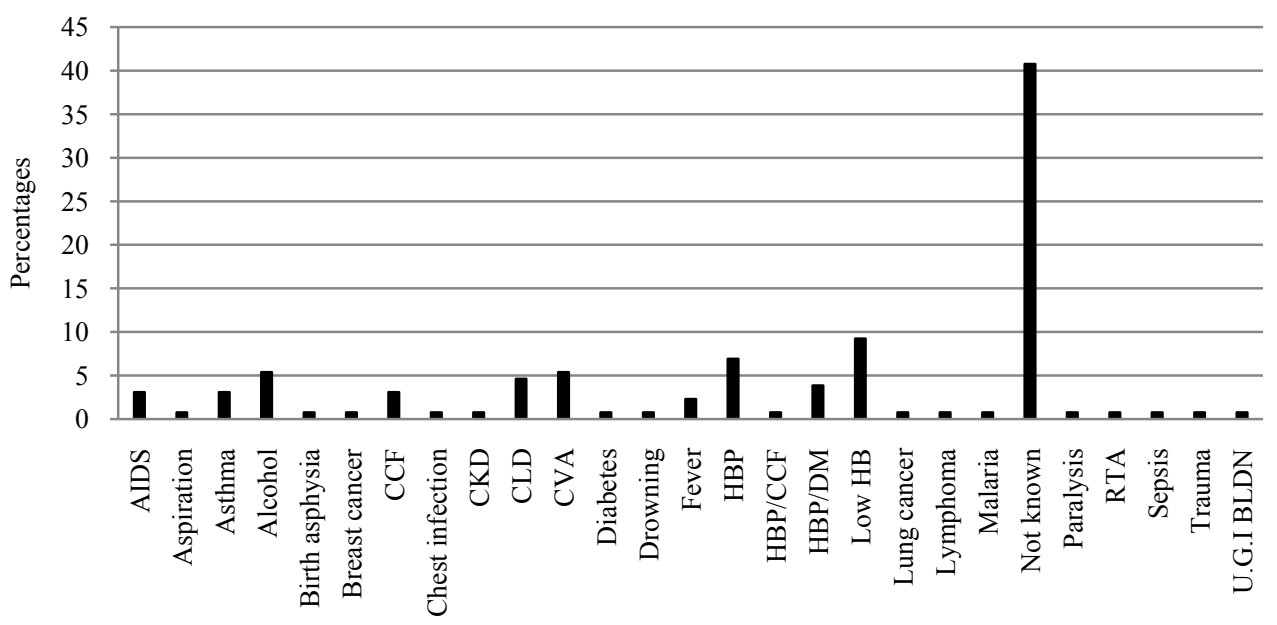

Clinical conditions

Figure 3. Clinical conditions associated with BID patients. $\mathrm{CKD}=$ Chronic kidney disease; $\mathrm{CLD}=$ Chronic liver disease; CVA = Cerebrovascular accident; RTA = Road traffic accident; HBP $=$ High blood pressure; $\mathrm{CCF}=$ Congestive cardiac failure; $\mathrm{DM}=$ Diabetes mellitus; $\mathrm{HB}=$ Hemoglobin; AIDS = Acquired immuno deficiency syndrome; U.G.I BLDN = Upper gastrointestinal bleeding.

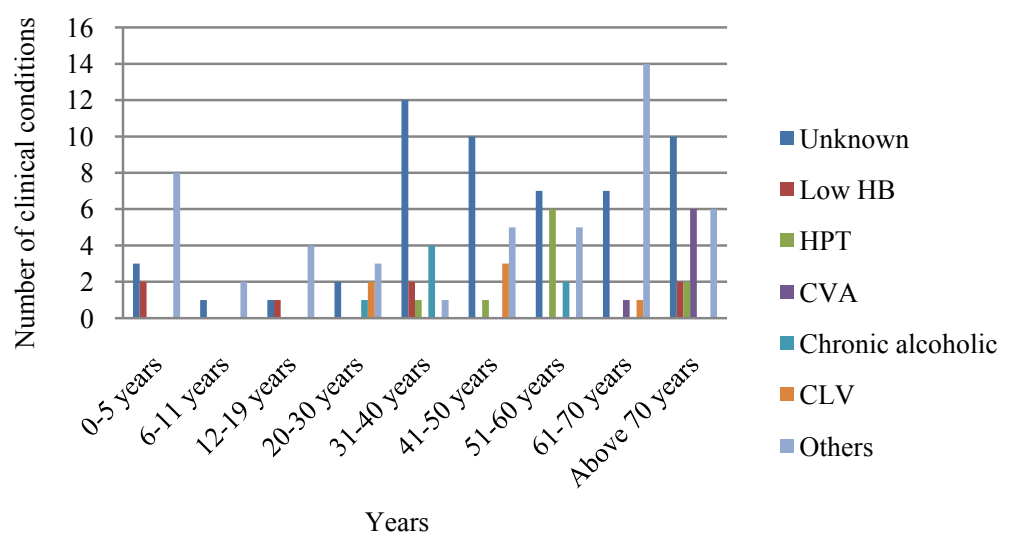

Figure 4. Distribution of clinical condition among age groups. HB = Hemoglobin; HPT = Hypertension; $\mathrm{CVA}=$ Cerebrovascular accident $\mathrm{CLV}=$ Chronic liver disease. 


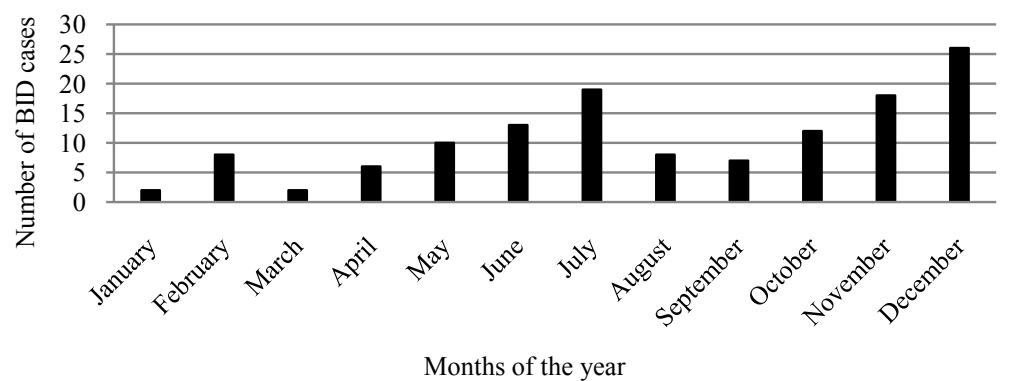

Figure 5. Distribution of cases of BID in months.

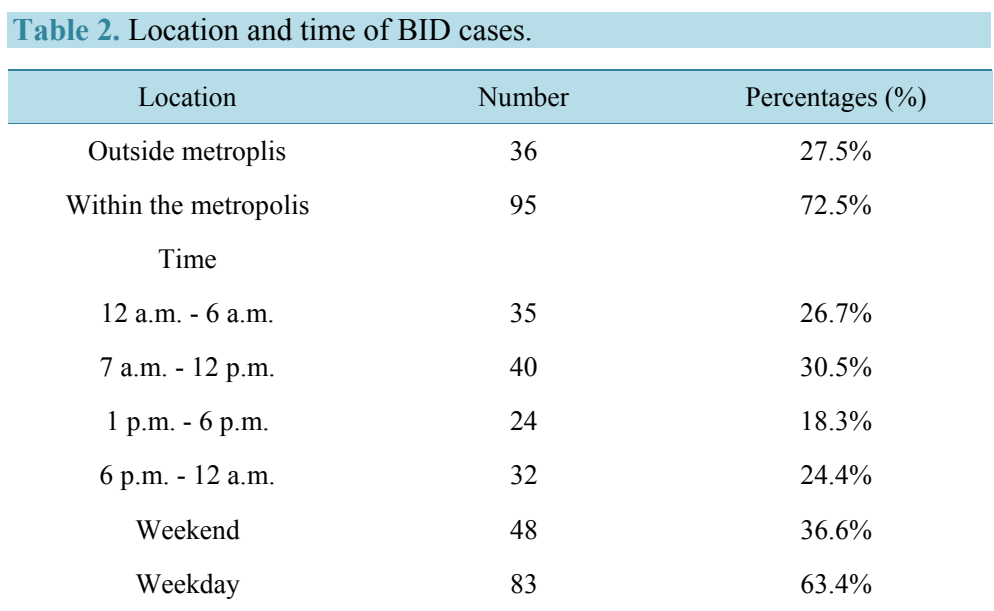

\section{Discussion}

This study evaluated cases of BID in the accident and emergency unit of the Effia-Nkwanta Regional Hospital. The prevalence of brought in dead cases was $31.1 \%$ which is very high in comparison with similar studies done in two separate urban settings in Nigeria. In these studies, the prevalence of BID was 3.5\% at the University of Port-Harcourt teaching hospital and 4.2\% at the University of Calabar Teaching Hospital [2] [3]. There are many reasons for this significant difference in prevalence which might include differences in the study settings. Effia-Nkwanta Regional Hospital is a secondary health institution and the only referral point in the whole western region serving the twenty two districts. Thus, there are no other secondary healthcare institutions able to share or relieve the burden of these mortalities. This is not so for the universities of Calabar and Port-Harcourt teaching hospitals as they are tertiary institutions with shared responsibilities with other secondary referral centers in the area.

The lowest age group presenting as BID are older children between the ages of 6 and 11 years and the highest group are patients above 70 years. The high rate of BID above 70 years might be explained by the fact that at this age group most of these patients are chronically ill, bedridden or moribund and more so relatives might not have the time to take care of them thus, would bring them to hospital dead [4] [5]. In this study, majority of the BID cases $(40.8 \%)$ had no known clinical condition as their relatives claimed they were apparently healthy before they died suddenly. This finding is in agreement with the findings of Cummings, where he recorded a prevalence of $34 \%$ for sudden death as the commonest cause of non-traumatic cause of death [6].

Cases without any known clinical condition were higher in patients over 30 years and highest $(22.6 \%)$ in patient in the age bracket from 30 to 40 years. This is an alarming finding as these age groups are usually the vibrant young adults who are in the prime of their lifetime. This might probably be due to insidious undiagnosed cardiovascular diseases and hypertension which are gradually becoming more prevalent in young adults in sub-Saharan Africa [7]-[9], or other ailments that may have been missed since the patients were brought in dead.

Trauma related BID cases and road traffic accidents were very minimal in this study. Road traffic accident cases are common findings in the accident and emergency unit of this hospital. Probably the majority of these 
accident cases were not so severe as to cause death or require the patient to be brought in dead. The highest burden of BID cases was seen in the month of December in this study. The month of December usually is a busy month full of festivities and lots of activities that are associated with holidays like Christmas, Salah and New Year celebrations. Preparations for the holidays usually start two months before the month of December. It is likely that most patients might undermine their health, turn deaf ears to the warning of their bodies and some will not keep their hospital appointments at this time [10]. All these measures are commonly done in this area to save time and money that will be utilized for the activities of the festive period.

The majority (72.5\%) of the brought in dead cases lived within the metropolis. This finding is not encouraging as it might reflect a practice of poor health seeking behavior among the people in the metropolis. Distance to hospital has been found to directly affect mortality, as sick patients who are far from hospitals have reduced chance of survival when they reach the hospital [11]. However in this study, the majority of these BID cases are living within the metropolis; thus suggesting that distance alone might not be the only reason for delay in patient arrival to hospital but a combination of psychological, social and economic factors [12] [13].

A limitation of this study is that it might not fully analyze the factors influencing the BID cases. Hence, there is a need for further extensive analytical studies to critically look at other factors that might influence the BID scenario in similar settings. BID cases are certainly influenced by a lot of pre-hospital factors. This study showed that the prevalence of BID was high in this community compared to other studies done in neighboring African countries. Other findings include 1) the elderly were more prone to be brought in dead, 2) sudden death was highest among young adults, 3) the cases of BID were highest in the festive period of December and 4) the majority of the BID lived within the metropolis.

\section{Conclusion}

This study indicates that Effia-Nkwanta Regional Hospital, the only referral hospital in the region, is grossly overburdened in handling the healthcare needs of the region. There is an urgent need to upgrade other hospitals in various districts of the South-Western region of Ghana, in order to take some of these responsibilities. This study also underscores the point for aggressive health promotion and health education in the population to increase and instill health seeking behavior, as this will help to prevent cases of avoidable sudden death, especially in young adults.

\section{Acknowledgements}

The authors show appreciation to all record unit staff of Effia-Nkwanta Regional Hospital.

\section{References}

[1] Sudnow, D. (1967) Dead on Arrival. Transaction, 5, 36-43.

[2] Ekere, A.U., Yellowe, B.E. and Umune, S. (2005) Mortality Patterns in the Accident and Emergency Department of an Urban Hospital in Nigeria. Nigerian Journal of Clinical Practice, 8, 14-18.

[3] Ugare, G.U., Ndifon, W., Bassey, I.A., Oyo-Ita, A.E., Egba, R.N., Asuquo, M. and Udosen, A.M. (2012) Epidemiology of Death in the Emergency Department of a Tertiary Health Centre South-South of Nigeria. African Health Sciences, 12, 530-537.

[4] Boult, C., Kane, R.L., Louis, T.A., Boult, L. and Mccaffrey, D. (1994) Chronic Conditions That Lead to Functional Limitation in the Elderly. Journals of Gerontology, 49, M28-M36. http://dx.doi.org/10.1093/geronj/49.1.M28

[5] Brody, E.M. (1985) Parent Care as a Normative Family Stress. Gerontologist, 25, 19-29. http://dx.doi.org/10.1093/geront/25.1.19

[6] Cummings, P. (1990) Cause of Death in an Emergency Department. American Journal of Emergency Medicine, 8, 379384.

[7] Amakiri, C.N., Akang, E.E., Aghadiuno, P.U. and Odesanmi, W.O. (1997) A Prospective Study of Coroner's Autopsies in University College Hospital, Ibadan, Nigeria. Medicine, Science and the Law, 37, 69-75.

[8] Aligbe, J.U., Akhiwu, W.O. and Nwosu, S.O. (2002) Prospective Study of Coroner's Autopsies in Benin City, Nigeria. Medicine, Science and the Law, 42, 318-324.

[9] Shavadia, J., Yonga, G. and Otieno, H. (2012) A Prospective Review of Acute Coronary Syndromes in an Urban Hospital in Sub-Saharan Africa. Cardiovascular Journal of Africa, 23, 318-321. http://dx.doi.org/10.5830/CVJA-2012-002 
[10] Ike, S.O. (2008) The Pattern of Admissions into the Medical Wards of the University of Nigeria Teaching Hospital, Enugu (2). Nigerian Journal of Clinical Practice, 11, 185-192.

[11] Nicholl, J., West, J., Goodacre, S. and Turner, J. (2007) The Relationship between Distance to Hospital and Patient Mortality in Emergencies: An Observational Study. The Journal of Emergency Medicine, 24, 665-668. http://dx.doi.org/10.1136/emj.2007.047654

[12] Campbell, S.M. and Roland, M.O. (1996) Why Do People Consult the Doctor? The Journal of Family Practice, 13, $75-$ 83. http://dx.doi.org/10.1093/fampra/13.1.75

[13] Walsh, J.C., Lynch, M., Murphy, A.W. and Daly, K. (2004) Factors Influencing the Decision to Seek Treatment for Symptoms of Acute Myocardial Infarction: An Evaluation of the Self-Regulatory Model of Illness Behaviour. Journal of Psychosomatic Research, 56, 67-73. http://dx.doi.org/10.1016/S0022-3999(03)00082-5 